\title{
Hydromorphological Mapping and Analysis for Characterizing Darfur Paleolake, NW Sudan Using Remote Sensing and GIS
}

\author{
Samy Ismail Elmahdy \\ Department of Civil Engineering, Faculty of Engineering, Universii Putra Malaysia (UPM), Serdang, Malaysia \\ Email: Samy903@yahoo.com
}

Received August 8, 2011; revised October 16, 2011; accepted November 15, 2011

\begin{abstract}
The north-western part of Sudan, which is the driest region on earth has revealed newly surface and near surface paleodrainage network underneath sand sheets indicating the possibilities for economic groundwater reservoirs. Advanced Space-born Thermal Radiometer (ASTER), the Shuttle Radar Topography Mission (SRTM 90 m) DEMs and Quickbird images corroborate the presence of surface and near surface paleodrainage network. Bivariate quadratic surfaces with moving window size of $3 \times 3$ were fitted to the SRTM DEM. The second derivative surface curvature was calculated to reveal landform classes that may receive most of fossil water. The results showed that the new unnamed depression which recharges by a longitudinal paleodrainage network may receive vast amount of groundwater during humid phases. The results demonstrate that the D8 and curvature algorithms are very efficient tools for revealing and characterizing hydrological elements in arid and semi-arid regions and they provide information for hydrological exploration in remote deserts over large scale prior to geophysical survey.
\end{abstract}

Keywords: Darfur; Groundwater; Sudan; Paleodrainage Network

\section{Introduction}

North-western Sudan is sandy desert and shallow reservoirs are drying up and groundwater levels are declining due to over pumping and exploitation to meet the demand of an ever increasing drought affected population built up [1]. About $80 \%$ of the inhabitants of Sudan depend on groundwater for their livelihood almost all the year round.

Nowadays, the groundwater could greatly affect the urban and reclamation development [2-5]. However, during the late Quaternary, the region was flooded as indicated by lacustrine deposits and playa carbonate deposits, dried extinct drainage patterns, flora and signs of prehistoric human occupation [2,6-13].

Due to the study area being extremely dry and partly inaccessible, it is practically impossible to reveal and explore economic amounts of groundwater on a large scale through traditional methods. Digital Elevation Models (DEMs) (NASA Shuttle Radar Topography Mission-SRTM) enable more reliable analysis in many applications than before, especially in remote arid and semi-arid regions such as the study are SRTM data is widely used as a main topographic dataset to evaluate regional scale hydrology, providing accurate and consistent elevation data on a worldwide basis [14]. Prelimi- nary analyses done by [15] suggests that SRTM DEM in low relief areas over large scale is likely more accurate than the mission specifications. For this reason, SRTM DEM has a great and partly unrealized potential for hydrologic applications.

The eastern Sahara represents an ideal location for revealing near surface geological and geomorphological features and groundwater exploration over large scale using SAR data.

The depth of penetration near surface paleodrainages using C-band radar is up to $0.5 \mathrm{~m}[16,17]$. This is because of the scarcity of lakes (water bodies), rainfall, vegetation cover, low topography and low soil moisture content. Few studies have been applied for mapping paleodrainage network in the Northern Darfur depression, Sudan. [18] has mapped paleolake shorelines and regional buried paleodrainage network over a wide area in Northern Darfur using SRTM DEM and RADARSAT-1 images. Paleolake deposits [2,8], drainage network delineated from Shuttle Imagine Radar (SIR-A) images using visual interpretation [2,8], mapping the Northern Darfur basin using GPS and field observation and LANDSAT image [13].

According to them, these features have developed during the late Quaternary when the climate was wetter phases 
than it is today as indicted by lacustrine deposits and playa carbonate deposits, dried extinct drainage patterns, flora and signs of prehistoric human occupation.

The use of digital elevation models (DEMs) through geographical information systems (GIS) is a powerful approach in this matter, since automatic methods to analyze topographic features are allowed, with both operational and quality advantages. While GIS-based feature extraction are processed with all advantages of digital resources (speed, repeatability and computer integration with other databases), the reduction of manual intervenetions (and thus subjectivity) and the possibility of parametric approach represent qualitative distinctions from interpretative-based methods [19-22].

In watershed studies, GIS modeling of DEMs is often applied to erosion estimates [23], in which the automatic extraction of its related variables consists as important field of research [24]. Directly concerned to the comprehension of watershed drainage structure, watershed partition [25] and the identification of terrain units [26] are important tasks to be supported by DEM analysis.

This study presents different approach based on automatic and semiautomatic algorithms with verification of visual interpretation in high resolution satellite images. More specifically, this study used D8 algorithm, terrain category by elevation and Wood algorithms with two different sensors, SRTM DEM of spatial resolution $\sim 90$ $\mathrm{m}$ and Quick Bird image of spatial resolution $0.6 \mathrm{~m}$, for delineation and analysis the surface and near surface paleodrainage and depressions that drained and veined the western part of Sudan. Hence, the main goals of this study are to:

1) Extract of the surface and near surface paleodrainage network in the north-western part of Sudan from 90 m DEM using D8 algorithm over large scale.

2) Precise mapping of paleo-shorelines of the Northern Darfur depressions from 90 m DEM using terrain category algorithm.

3) Classify the landform classes (morphometric features) from $\sim 90 \mathrm{~m}$ DEM using maximum curvature algorithm.

\section{Study Area}

The Darfur region occupies one fifth of the area of Sudan comprising approximately 500,000 square kilometers. The region borders Libya to the northwest, Chad to the west, and the Central African Republic to the south-west. Extending from north to south, the climate in Darfur varies from extremely arid, semi-arid to the wet semi-tropic climate in the southern part [1].

The rainfall varies from zero in the north and gradually increases southwards reaching $800 \mathrm{~mm}$ annually and rises up to $1000 \mathrm{~mm}$ Jebel Marra highlands (Figure 1). The water table lies between $10 \mathrm{~m}$ to $1000 \mathrm{~m}$ deep [2]. The amount of groundwater recharge in Sahara Nubian and Baggara basin have been estimated to be $20.6 \times 106 \mathrm{~m}^{3}$ and $155 \times 106 \mathrm{~m}^{3}$ respectively (Table 1).

The groundwater aquifer thickness varies between 250 $\mathrm{m}$ and $550 \mathrm{~m}[1,5,27]$. The main lithology varies from unconsolidated rocks such as Nubian sandstone with high to low hydrological importance to fractured rocks with medium to low hydrological importance (Figure 1).

\section{Material and Methods}

\subsection{Data Sources and Pre-Processing}

Three remotely sensed data were used in this study: a SRTM DEM of $\sim 90 \mathrm{~m}$ spatial resolution; the Quick bird image of spatial resolution $0.6 \mathrm{~m}$. The SRTM data product is one of the most valuable global resources of topographic data to date [28]. However, the original [29] DEMs contain holes that represent no data or attenuated measurement of elevation. These holes affect the accuracy of hydrological modeling which requires a continuous flow surface [28]. The new versions of SRTM DEMs $[30,31]$ are the result of interpolation efforts of the unedited SRTM DEM version 2 ( $\sim 90 \mathrm{~m})$. These SRTM data has been chosen because the depth of penetrating near surface paleodrainages is up to $0.5 \mathrm{~m}$ [16-18]. Near surface features (palaeolake and paleodrainages) appear dark in SRTM data. The second set was Quickbird images of spatial resolution $0.6 \mathrm{~m}$ and available as a geographic (long/lat) projection, with the WGS84 horizontal datum currently available from US department of State Geographer and Google earth browser [32]. These images were used to compare visually the textural features (paleodrainage networks) evident in SRTM and to decide if patterns expressed by high-resolution optical data are different. The third data set was The Advanced Spaceborne Thermal Emission and Reflection Radiometer (ASTER) DEM of spatial resolution $30 \mathrm{~m}$ is distributed as a geographic (long/lat) projection, with the WGS84 horizontal datum currently available from the Earth Remote Sensing Data Analysis Center (ERSDAC) database [33].

The auxiliary data in terms of hydrological map of Sudan [34], Quickbird images and ASTER DEM was used to compare visually the textural features (paleodrainage networks) evident in STRM and to decide if patterns expressed by high-resolution remotely sensed data are different.

\subsection{Delineation of the Northern Darfur Paleolake and Its Depressions}

Four sets of terrain category by elevation and shaded relief maps were generated from DEM at sun azimuth (compass direction to the sun) of $335^{\circ}$ and sun elevation 


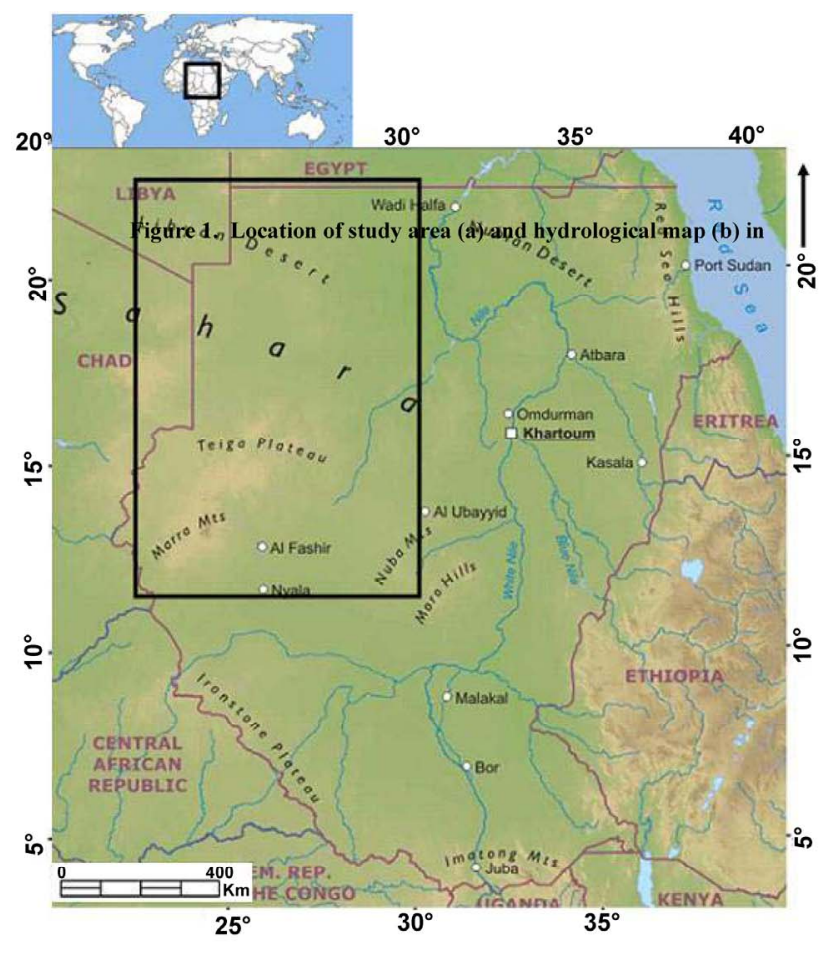

(a)

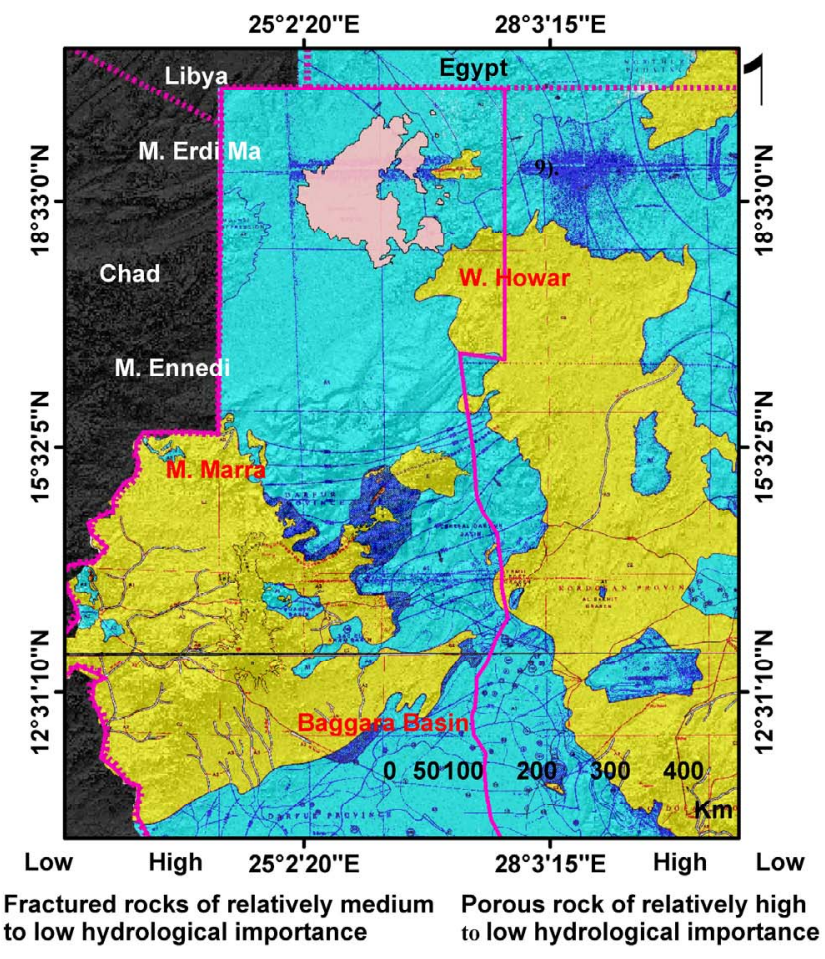

(b)

Figure 1. Location of study area (a) and hydrological map (b) in the north west of Sudan (after hydrological map of Sudan, 1989).

Table 1. Lithological formation and their hydrological characteristic (Omer, 2002).

\begin{tabular}{cccc}
\hline Basin & Aquifer thickness $(\mathrm{m})$ & Water level $(\mathrm{m})$ & Amount of water recharge $\left(10^{6} \mathrm{~m}^{3}\right)$ \\
\hline Sahara Nubian & $300-500$ & $10-50$ & 20.6 \\
Central Darfur & $250-550$ & $25-100$ & 47.6 \\
Western Kordofan & $300-500$ & $50-70$ & 15 \\
Baggara & $300-500$ & $10-75$ & 155 \\
\hline
\end{tabular}

(elevation angle for the sun) of $45^{\circ}$. For the boundary and shoreline delineation of northern Darfur paleolake, 35 times vertical exaggeration was applied and paleolake boundaries and shorelines were represented in different colors to facilitate discrimination and visualization.

Boundaries and shorelines of the Northern Darfur paleolake were manually screen digitized in each thematic map of terrain category and shaded relief and then the resulting boundaries and shorelines maps were merged into one. The total area of each boundary and shoreline (polygon) was then calculated using Envi v.4.5 and the open source MicroDEM version 10 software [35].

\subsection{Extraction of Surface and Near Surface Paleodrainage Networks}

For a semi-automated method, it is necessary to implement algorithms which reveal linear geomorphometric fea- tures quantitative, numerical attribute of topography [36].

At a more accuracy of hydrological modelling, it is importantly to eliminate the sinks (faulty values) in DEM by means of filtration through fill in algorithm so there no runoff interruption [37,38].

To extract the surface and near surface paleodrainage network, the deterministic-eight node (D8) single flow direction algorithm [39,40] was used. The D8 algorithm works well to mimic the flow of rivers and streams, and flow convergence in valleys [29]. The algorithm determines into which neighboring pixel any water in a central pixel will flow naturally. Flow direction in a DEM is calculated for every central pixel of input blocks of a $3 \times$ 3 window, all the time comparing the value of the central pixel in the window with the value of its eight neighbors. Then, find the steepest slope and downhill slope of a central pixel to one of eight neighboring pixels. 
The threshold definition (stream definition) is performed after flow direction and flow accumulation are determined. Selection of a threshold value depends on desired performance [41]. In this study, a threshold of 5000 cells was chosen as the resulting drainage was found to correspond with those delineated in the STRM DEM.

Extraction and delineation of surface and near surface paleodrainage network is implemented in the commercial ArcGIS v9.2 software [41]. The new resultant paleodrainage network maps were mosaiced using Envi. v. 4.5 software. For better analysis and perspective viewing, the paleodrainage network was draped over shaded relief reflectance generated from the DEM.

\subsection{Classifications of Landform and Relief Shape}

Identification of landform express paleoflow accumulation and paleoflow dissipation zones can be realized by curvatures maps of Wood's algorithm, which is basically based on terrain parametrization analysis of DEM. In terrain parameterization analysis, the second derivatives of DEM (Table 2) are the basic parameters of morphometric analysis and landform classification [42-44].

To calculate landform classes, a $3 \times 3$ local window is passed over the DEM and slope change of a central pixel in relation to its neighbors is derived by a bivariate quadratic function as follows:

$$
z=a x^{2}+b y^{2}+c x y+\mathrm{d} x+e y+f
$$

where $x$ and $y$ are the Cartesian coordinates, and the letters $a$ through $f$ are the coefficients of the polynomial that contain information on relief attributes [42,43]. Curvature parameters can be separated into two orthogonal components, profile and plan curvatures [34].
Wood (1996) used two alternative parameters, maximum and minimum curvatures if the slope normal is inclined and an aspect can be calculated. For example, plan convexity or planc (intersecting with $X Y$ plane), minimum curvature or minic and maximum curvature maxic (intersecting in any plane). Wood (1996) identified geomorphometric features based on unique sets of slope steepness, cross sectional maximum and minimum curvatures. Wood (1996) defined set of rules to classify DEMs into landform classes (Table 3).

In the results, valleys and channels have the most negative values for minimum curvature and ridges have the most positive value for maximum curvature. In other words, the curvature has negative values mean convex shapes and paleoflow dissipation and curvature has positive values mean concave ones and paleoflow accumulation. Identification and classification of landform is implemented in the open source MicroDEM v.10 software.

To evaluate the hydrological setting and areas of groundwater recharge for each depression, the percentage of landform classes (channels, pits and/or micro-depressions) per total surface area of each depression were calculated.

\subsection{Validation of the Extracted Paleodrainage Network}

Three validation methods were constructed to assess the accuracy of revealed features. In the first validation; the revealed paleodrainage network from SRTM DEM and those from Quickbird images [32] and ASTER DEM [33] were correlated visually. The validation was performed by comparing the textural features (surface and near surface paleodrainage network) and deciding if these patterns are different. In the second validation method, the

Table 2. Morphometric parameters (Evans, 1972; Wood, 1996; Shary et al., 2002).

\begin{tabular}{|c|c|c|}
\hline Morphometric parameter & Formula & Description \\
\hline Slope steepness (degrees) & $\arctan (\operatorname{sqrt}(d 2+e 2))$ & $\begin{array}{l}\text { Magnitude of steepest gradient in both } \mathrm{X} \text { and } \mathrm{Y} \\
\text { directions. }\end{array}$ \\
\hline Maximum Curvature (1/m) & $n \times g \times(-a-b+\operatorname{sqrt}((a-b) 2+c 2))$ & In any plane \\
\hline MinimumCurvature (1/m) & $n \times g \times(-a-b-\operatorname{sqrt}((a-b) 2+c 2))$ & In any plane \\
\hline Profile Curvature (1/m) & $\begin{array}{c}n \times g \times(a \times d 2+b \times e 2+c \times d \times e) /(d 2+e 2)(1+ \\
(d 2+e 2)) 1.5\end{array}$ & $\begin{array}{l}\text { Vertical component in direction of aspect. } \\
\text { (Intersecting with the plane of } \mathrm{z} \text { axis and aspect } \\
\text { direction). }\end{array}$ \\
\hline Plan curvature (1/m) & $n \times g \times(b \times d 2+a \times e 2-c \times d \times e) /(d 2+e 2) 1.5$ & $\begin{array}{l}\text { Horizontal component in direction of aspect } \\
\text { (Intersecting with the X, Y plane). }\end{array}$ \\
\hline
\end{tabular}

Table 3. Morphometric features classification criteria (modified from Wood (1996)).

\begin{tabular}{cccc}
\hline Morphometric features & Slope $\left({ }^{\circ}\right)$ & Maximum curvature & Minimum curvature \\
\hline Ridge & $0,+$ va & + va & - va \\
pass & 0 & - va & - va \\
Channel & $0,+$ va & - va & - va \\
Pit (micro-depression) & 0 & \\
\hline
\end{tabular}


revealed surface and near surface paleodrainage network were compared to those in the previous study by [18]. In the third validation method, the resultant maps were compared with hydrological map of Sudan.

\section{Results and Discussions}

\subsection{Delineation of the Northern Darfur Paleolake Shorelines and Its Depressions}

The results of DEM processing and analysis (Figures 2-4) show the Northern Darfur paleolake is a multi-elevation depression (regional basin) and consists of seven depressions. These depressions are the unnamed depression, Al-Natrun, Nukhiela, Hammra, Oyo, Hussien and Wadi Fesh Fesh. The unnamed depression is located at an elevation ranges from $500 \mathrm{~m}$ to $540 \mathrm{~m}$ and occupies an area of about $2000 \mathrm{~km}^{2}$, Al Natrun depression is located at elevation $530 \mathrm{~m}$ and occupies an area of about 895.57 $\mathrm{km}^{2}$, the Nukhiela depression is located at an elevation of $540 \mathrm{~m}$ and occupies an area of about $713.8 \mathrm{~km}^{2}$, the Hussien depression is located at an elevation ranges from $470 \mathrm{~m}$ to $540 \mathrm{~m}$ and occupy an area of about $433.4 \mathrm{~km}^{2}$, the Fesh Fesh corridor is located at an elevation range from $530 \mathrm{~m}$ to $550 \mathrm{~m}$ and has flow path of $51.7 \mathrm{~km}$ in length, Hamra depression is located at an elevation ranges from $515 \mathrm{~m}$ to $535 \mathrm{~m}$ and occupies an area of about $252 \mathrm{~km}^{2}$, and the Oyo depression is located at an elevation range from $478 \mathrm{~m}$ to $530 \mathrm{~m}$ and occupies an area of about $286 \mathrm{~km}^{2}$.

These results are in contradiction with [18] who mapped the paleoshorelines of the Northern Darfur and its de- pressions from shaded relief maps and RADARSAT-1 images using visual interpretation. Geologically, the Northern Darfur paleolake and its depressions are probably results from intersections northeast-southwest and northwest-south east of regional fault zones, which serve as underground channels for upward transport deep seated fossil water to the land surface and downward transport to the deep aquifers [37]. So, some portions of the surface and near surface paleodrainage network routs can coincide with discharges of deep-seated fossil water pathways $[1,4,5,20,38,39]$.

\subsection{Extraction of Surface and Near Surface Paleodrainage Networks of North Western Sudan}

Figure 5 shows the resultant surface and near surface paleodrainage network map derived from DEM using D8 algorithm where the major paleodrainage network is represented by white and blue lines to facilitate the visual interpretation. The paleodrainage network map shows four tributaries (Wadis) drain the Northern Darfur paleolake. These features are the Uweinat tributaries (north) drain from Libyan and Egypt borders and end at Wadi Fesh Fesh, Hammra and Oyo depressions with bearing of N13E, the Erdi Ma tributaries (east) drain from the ErdiMa Mountain (Chad) and end at the unnamed depression with bearing of N60W. The Ennedi tributaries drain from Ennedi Mountain and end at the unnamed depression with bearing of S42W. They are very longitudinal and parallel in shape of about $350 \mathrm{~km}$ in length, and the

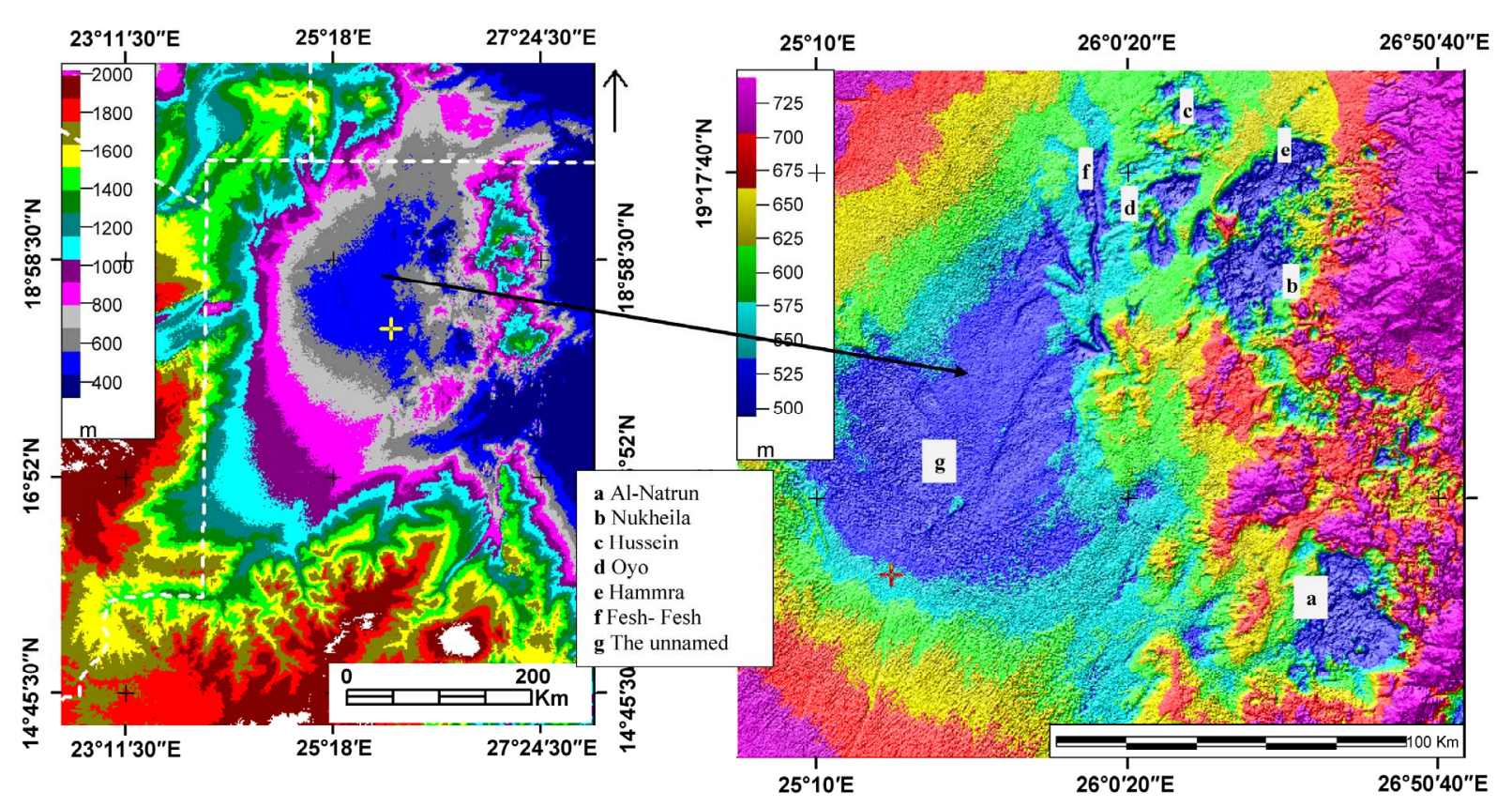

Figure 2. The Northern Darfur Basin (left) and its muti-elevation depressions are represented in different colors (right). These were derived from DEM using terrain category by elevation algorithm. 

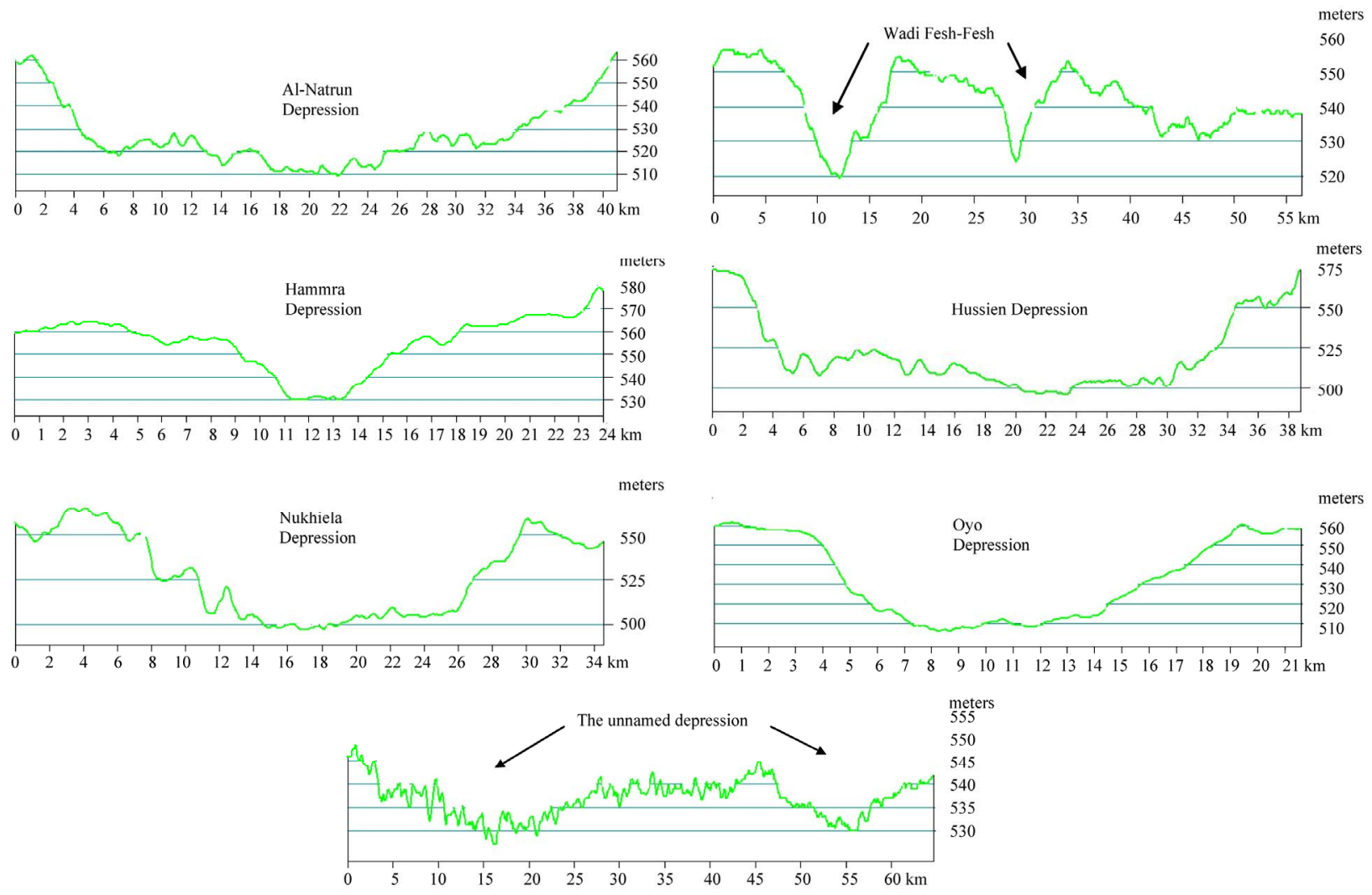

Figure 3. Topographic profiles performed from DEM of the Northern Darfur Depressions, Sudan.

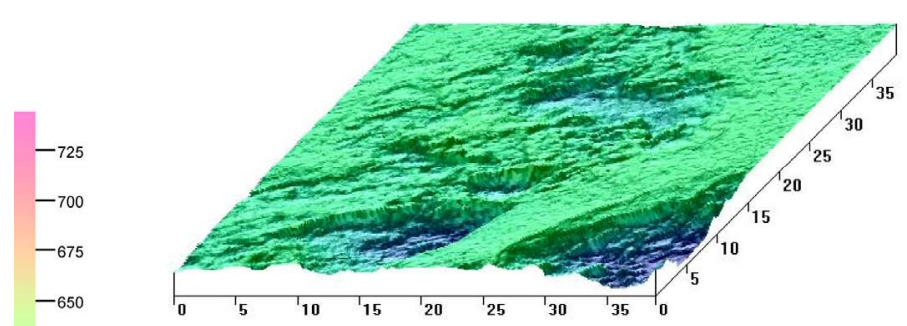

(a)

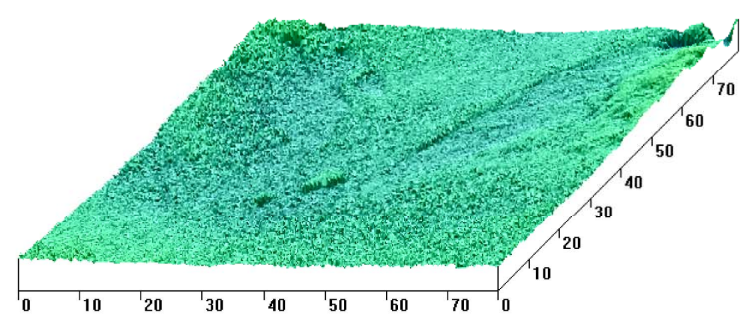

(c)

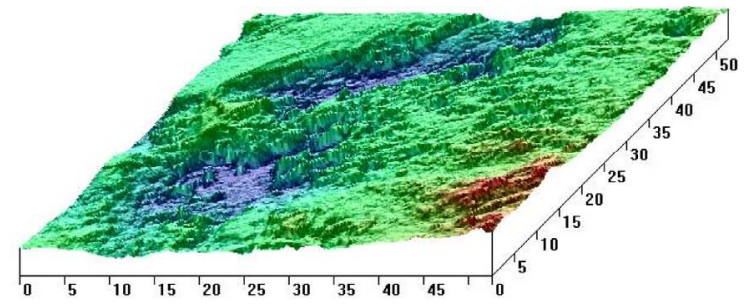

(b)

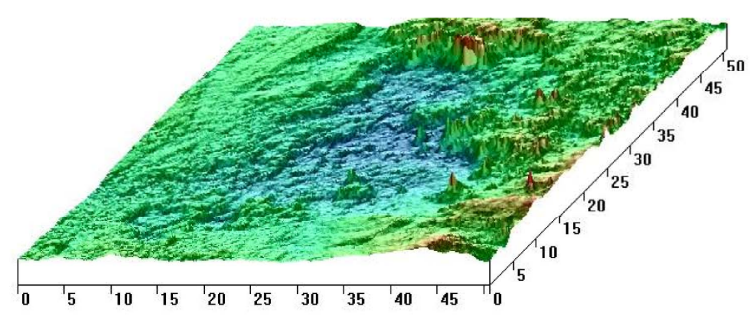

(d)

Figure 4. 3D views visualize (a) Hammra and Oyo depressions; (b) Hussien and Nukhilea depressions; (c) The unnamed depression; and (d) Al-Natrun depression.

Marra tributaries drain from Marra Mountain and end at Wadi Howar with bearing S65W.

Other tributaries drain from eastern flank of the Northern Darfur depression and end at Al Natrun depression, Nukheila depression and Hamrah depression with bearing of N72E. They are disconnected and dendritic in shape of about $71 \mathrm{~km}$ in length. They have well developed in late Quaternary (pre-Holocene period) of high fluvial activity, intensive precipitation, surface runoff and a longlive process that completed during wet phases.

Some of these paleodrainage networks were delineated from RADARSAT-1 C band, Shuttle Imagine Radar 


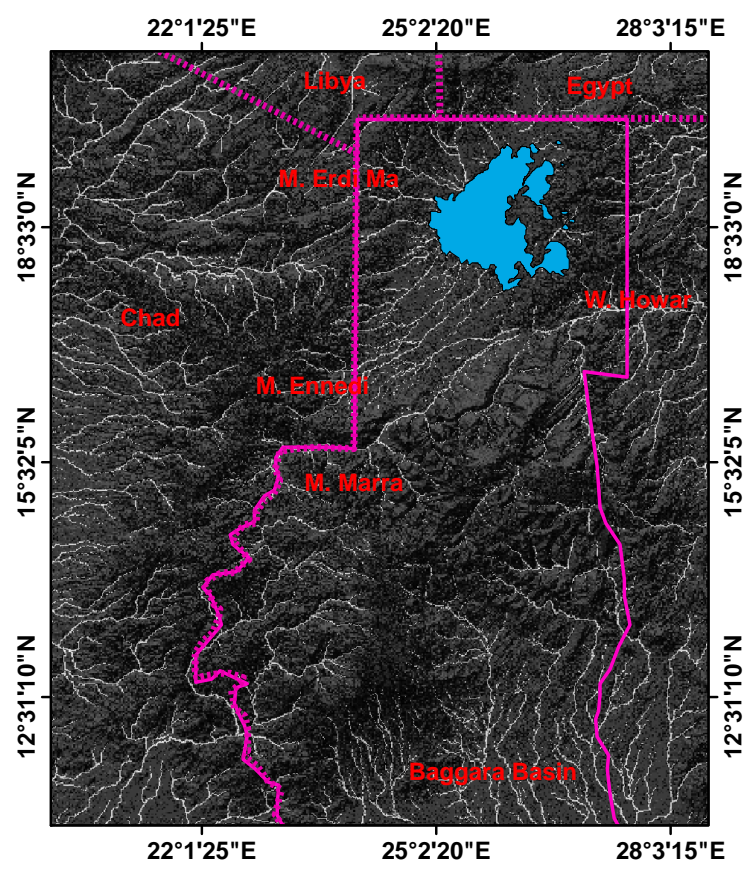

(a)

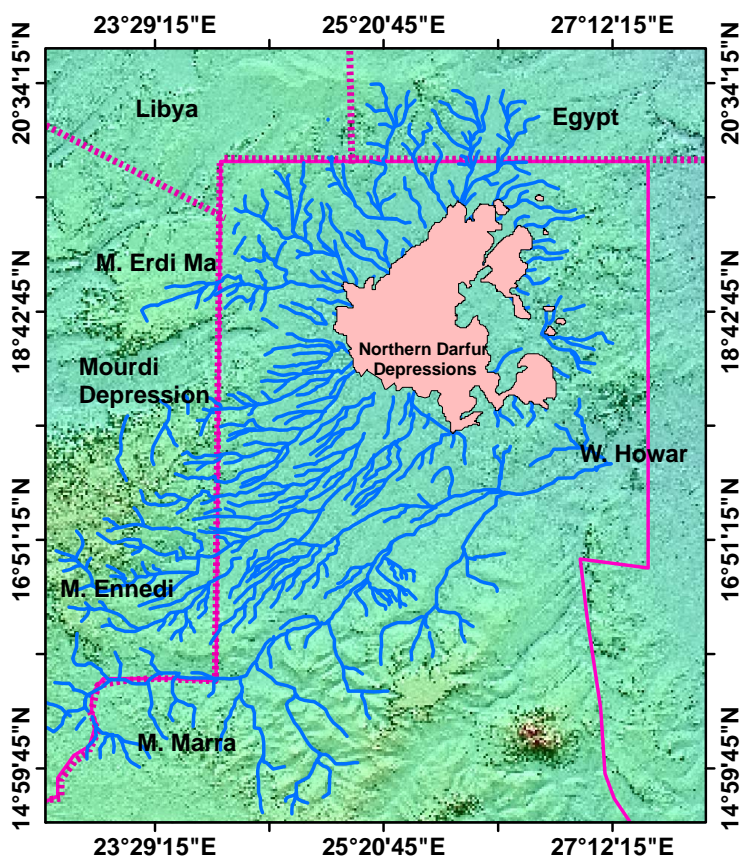

(b)

Figure 5. (a) Regional surface and near surface paleodrainage network extracted from DEM using D8 algorithm for the north-western apart of Sudan; and (b) Northern Darfur Paleolake.

SIR-A images and SRTM DEM using visual interpretation $[1,6-8,18]$, and field observation [2,13]. Hydrologically, the longitudinal and parallel paleodrainage network in shape clearly reflects flatter to gently slope for terrain and high rate of infiltration and dendritic paleodrainage network reflects steep slopes for terrain. Therefore, high rate of groundwater infiltration and accumulation are greater in flat areas [40]. Some of these paleodrainage networks have been related regional fault zones and joint systems and are extremely significant as they relate to preferential flow zones in the Nubian Sandstone [45-47].

Verification of the extracted paleodrianage network was made by comparing them with $0.6 \mathrm{~m}$ resolution Quickbird images (Figure 6). The paleodrainage network delineated from DEM using D8 algorithm coincide with paleodrainage network identified by visual interpretation in the high resolution satellite images and much more than revealed previously. The analysis of the paleodrainage network map and corresponding high resolution optical satellite images shows the powerful of the method to delineate and map the surface and near surface paleodrainage network in the western side of Sudan.

\subsection{Landform and Relief Shapes and Groundwater Flow Accumulation}

Figures 7 and 8 shows the resultant classification map where the major landform classes (e.g. ridges, channels, passes and pits) are represented in different colours to facilitate the interpretation. The most positive curvatures
$(>0)$ are represented by red color defines ridges, flanks of the channels and potential levees and over bank deposits (foot-wall of fault zones) with steep slopes and paleoflow dissipation zones, while the most negative curvature $(<0)$ are represented by blue color highlights axis of channels, valleys, thalwegs and paleoflow accumulation zones. Zero values for curvature correspond to planner area and paleoflow transition zones [36,44].

Curvature maps display a great help in bringing out the definition of channels, valleys and depressions, thus zones of groundwater accumulation [9,42-44,48]. These features are attributes which often highlight the regions where the rocks are broken and fractured and zones of groundwater accumulation. This is a regular result substantiating facts that paleodrainage network and accumulation zones often relate to fault intersections [45,49]. In general, in reality, classes with flat and high value for negative curvature and/or classes of zero values for curvature (e.g. pits, micro-depressions and channels) support low discharge of overland flow and high rate of infiltration. Thus, groundwater potentiality is much more in the flat and high negative curvature [49]. Flatter classes with zero value for curvature then will give more chance for groundwater accumulation.

Results of landform classification revealed that from total $2000 \mathrm{~km}^{2}$ coverage of the unnamed depression, about $40.2 \%$ are classified as channels, valleys and $9.4 \%$ are classified as pits and depressions with recharge area of about $993 \mathrm{~km}^{2}$ (Table 4). 
Table 4. The most groundwater recharge classes per total area in $\mathbf{k m}^{2}$ of the Northern Darfur depressions.

\begin{tabular}{cccccc}
\hline Depression & Channels $(\%)$ & Pit $(\%)$ & Total area $(\%)$ & Total area $\left(\mathrm{km}^{2}\right)$ & Recharge area $\left(\mathrm{km}^{2}\right)$ \\
\hline Un-named & 40.2 & 9.4 & 49.6 & 2000 & 922 \\
Al Natrun & 36.2 & 7.2 & 47.4 & 895.6 & 424.5 \\
Nukheila & 35 & 7 & 37 & 713.8 & 246.1 \\
W. Fesh Fesh & 34.3 & 7 & 41.3 & 461 & 170.5 \\
Hussein & 35.4 & 6.8 & 42.2 & 433.4 & 182.8 \\
Hamra & 35.7 & 7.1 & 37.3 & 252 & 95.2 \\
Oyo & 32.2 & 5.1 & 37.3 & 286 & 106.6 \\
\hline
\end{tabular}

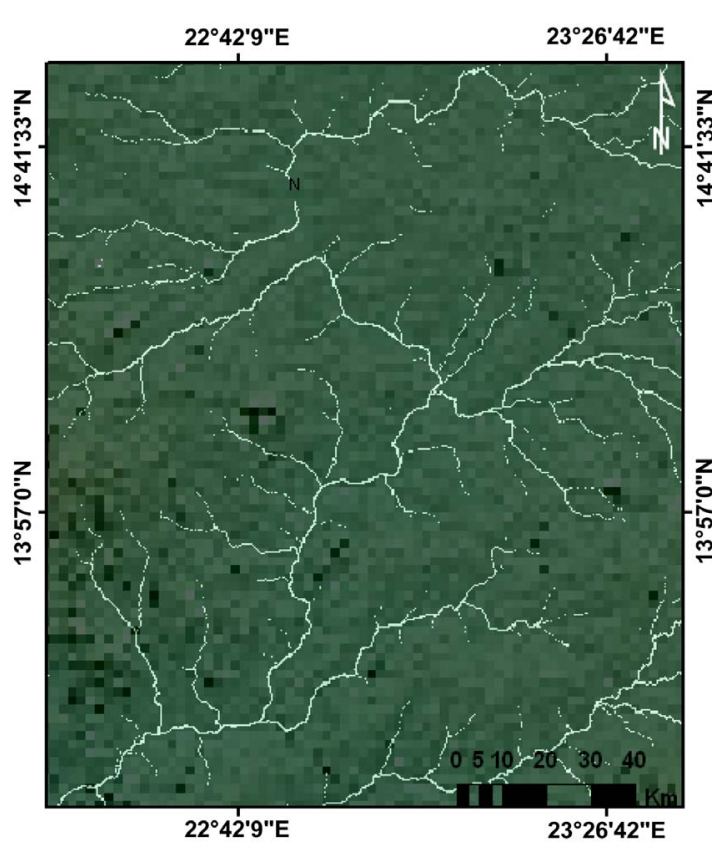

(a)

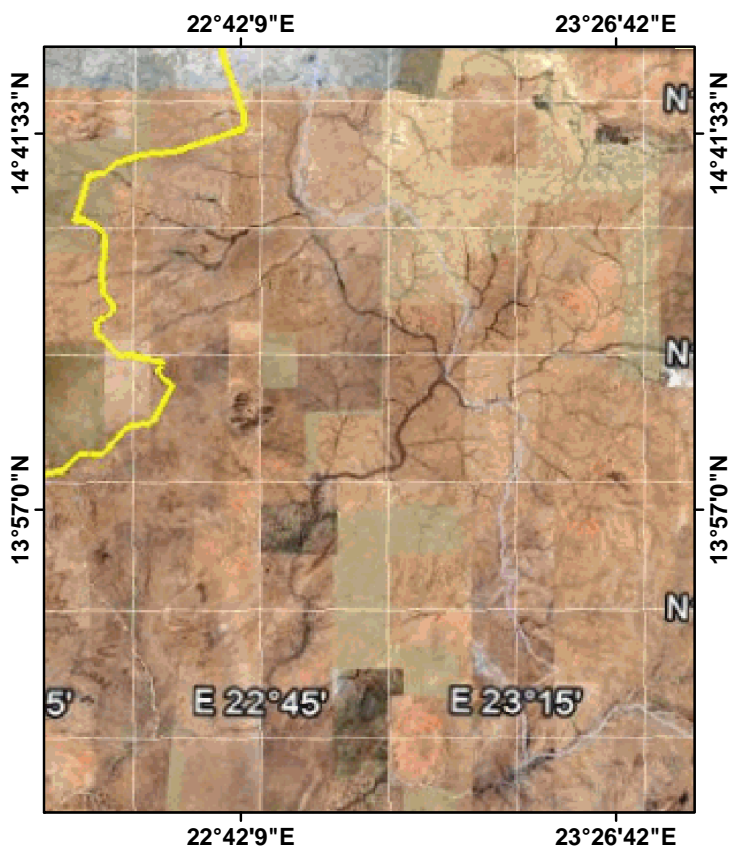

(b)

Figure 6. Two zooms of surface paleodrainage network derived from DEM using D8 algorithm (a) and corresponding $60 \mathrm{~m}$ resolution quickbird images $(\mathbf{b})$.

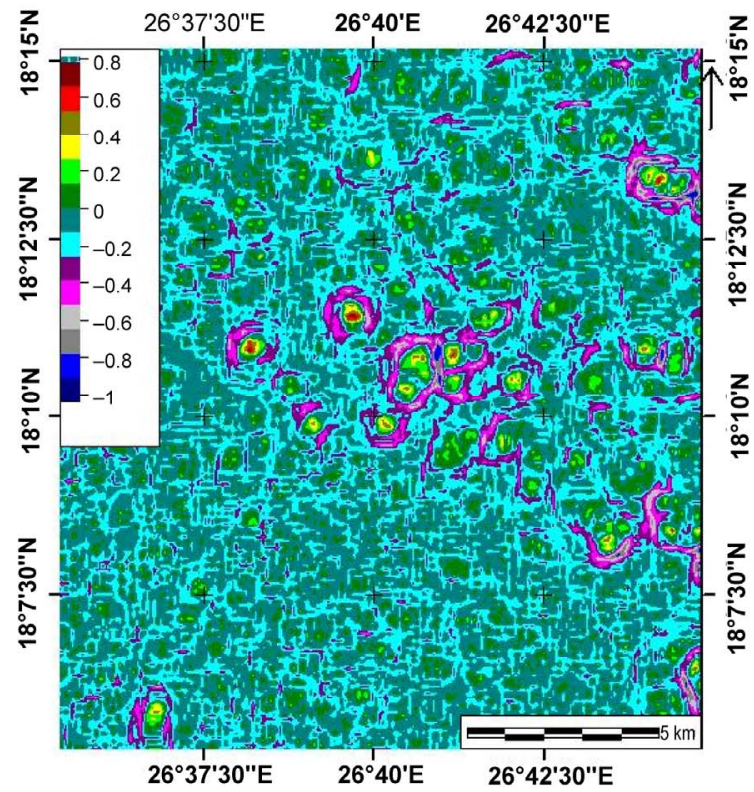

(a)

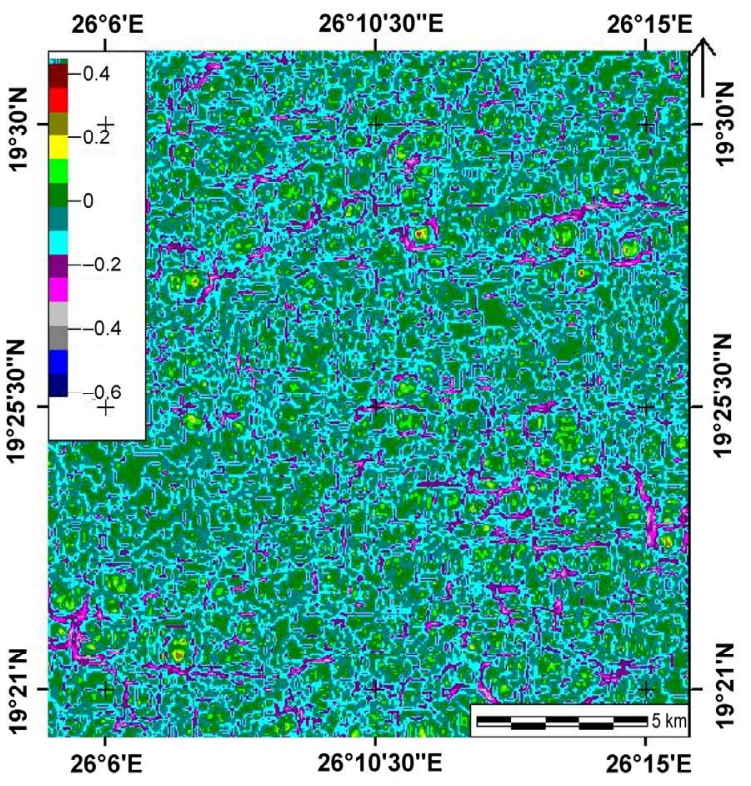

(b) 


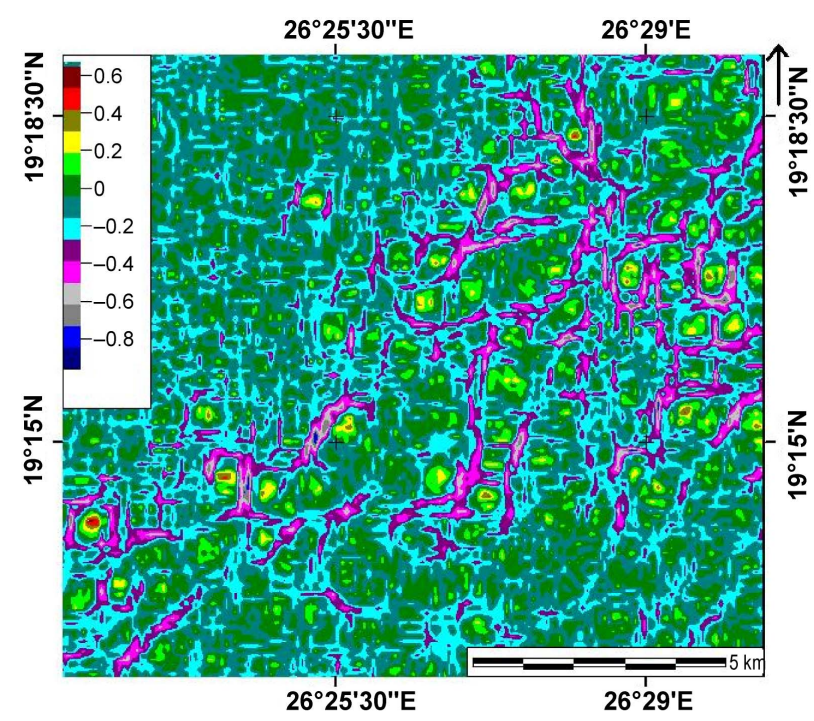

(c)

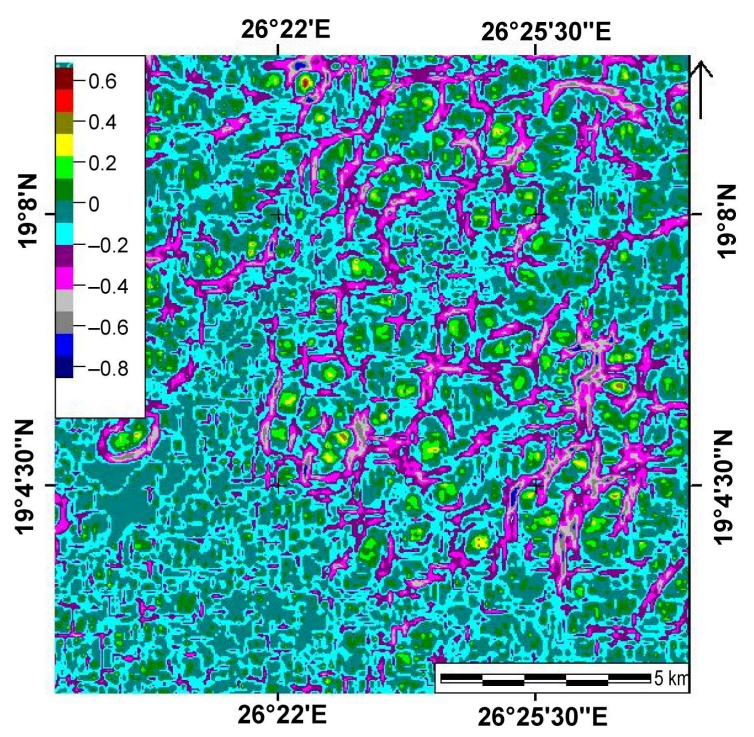

(d)

Figure 7. Maximum curvature maps derived from DEM using Wood's algorithm for (a) Al-Natrun; (b) Hammra; (c) Hussien depressions; and (d) Nukhiela depression.

This area has the highest percent of zones of accumulation, while the Wadi Fesh Fesh and Oyo depression have the smallest revealed area of zones of accumulation of approximately $34.314 \%$ and $32.272 \%$ respectively (Figure 9 and Table 4).

A multi-disciplinary approach using an integration of different datasets and algorithms is a powerful approach in the revealing and analysis surface and near surface paleodrainage network and flow accumulation zones that are closely associated with groundwater accumulation where there is a lack of hydrological and geological information.

The proposed approach can be used to extract and simulate several paleodrainage network conceal sand sheets. The analysis of the results and corresponding high resolution satellite images and hydrological map of Sudan (1989) shows the effectiveness of the method to map and analyze the overall pattern of the hydromorphological elements in the north western part of Sudan. The orientations of these features were found to be in the NW-SE, NE-SW, NNW-SSE, NNE-SSW and WNW-ESE directions and end in the seven revealed depressions. These were confirmed by patterns of streams and regional fault and hydrological unites that are reported in the geological and hydrological maps (Figure 1).

Future work will involve the application of both SAR data (e.g. ALOSPALSAR L band), and LANDSAT Enhanced Thematic Map $\left(\mathrm{ETM}^{+}\right)$images (e.g. thermal band) which will be applied in the future in order to delineate near surface paleodrainage network, fractured zones and soil moisture and enable a more hydrological model of the Northern Darfur paleolake to be constructed.

\section{Conclusions}

A set of automated algorithms were used successfully to reveal several new surface and near surface paleodrainage stream networks in the north western part of Sudan and northern Darfur paleolake (mutli-elevation paleolake), estimate its elevation and total area and classify landforms. The D8 algorithm was used to reveal surface and near surface paleodrainage networks much more than revealed previously. D8 algorithm allows revealing successfully geomorphometric features over large scale for the first time. These geomorphometric features are terms correspond to physical entities (surface and near surface paleodrainage networks). The supplementary data such as $30 \mathrm{~m}$ DEM produced from ASTER and $0.6 \mathrm{~m}$ Quickbird satellite images corroborate the presence of new surface and near surface paleolake and paleodrainage network. This is an important finding, confirming that the methods are reliable and produce consistent results. Results of landform classification revealed that from total $2000 \mathrm{~km}^{2}$ coverage of the unnamed depression, about $40.2 \%$ are classified as valleys and $9.4 \%$ are classified as pits and depressions with recharge area of about $992 \mathrm{~km}^{2}$. The results show the efficiency of the methods to identify, characterize and analyze hydromorphological elements (paleodrsainage network and landform classes) in the north western part of Sudan. The obtained results demonstrate that integrated methods, which are based on two different sensors and semi-automatic algorithms, are efficient for hydrological application in arid and semi-arid regions where inaccessible locations and scarcity of hydrological information is available.

The obtained maps can be used as a reference in 

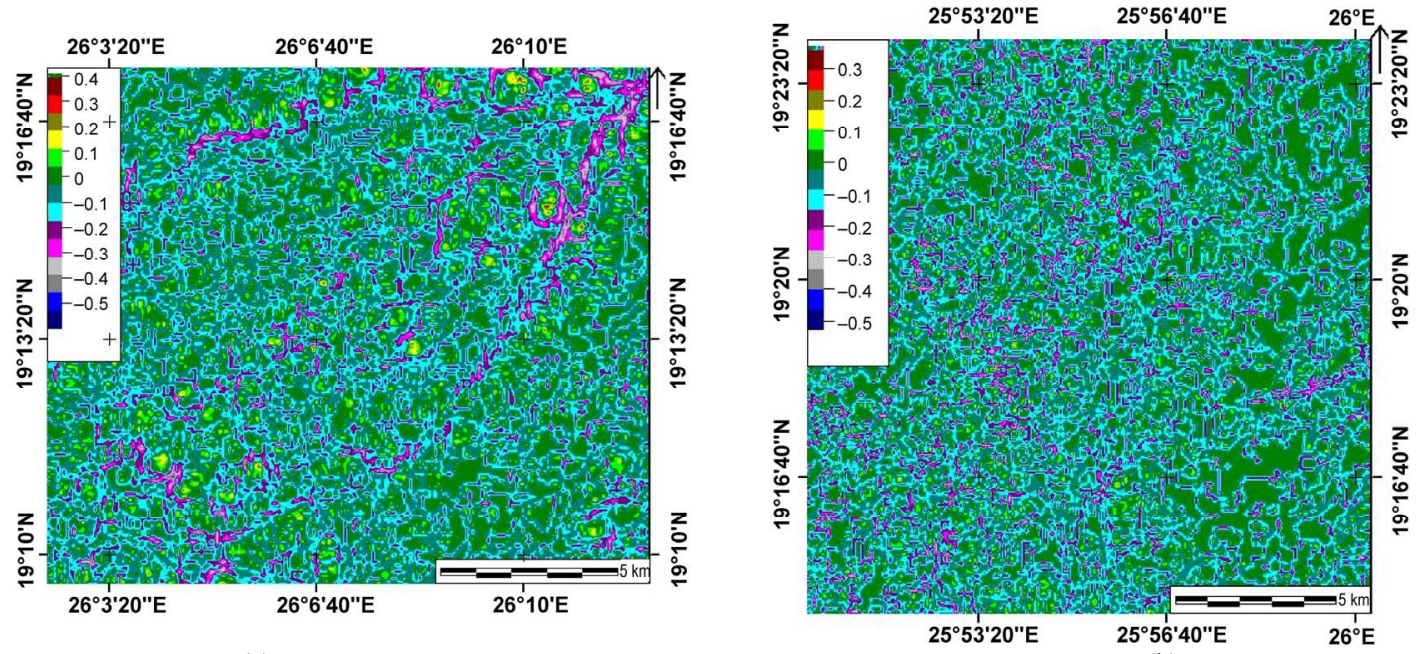

(a)

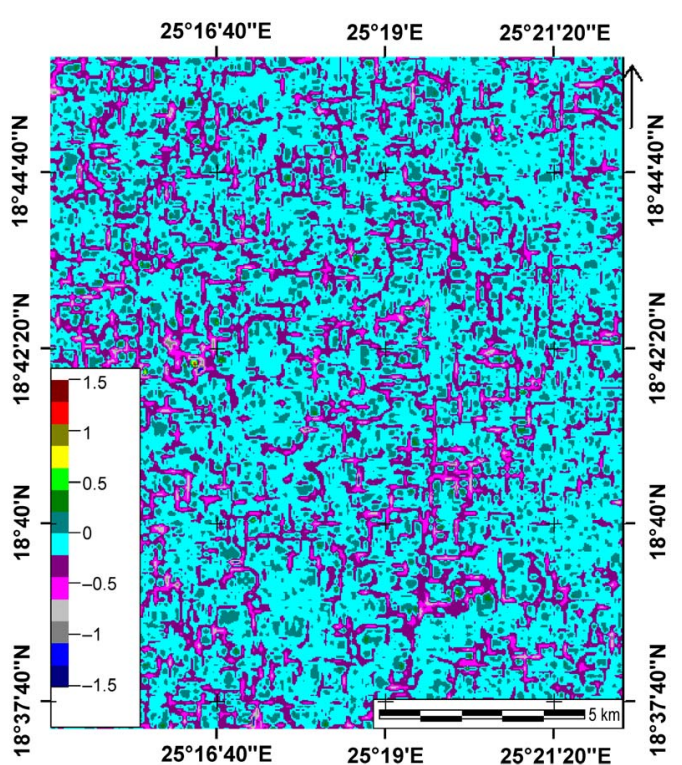

(c)

Figure 8. Maximum curvature maps derived from DEM using Wood's algorithm for (a) Oyo depression; (b) W Fesh Fesh; and (c) The un-named depression.

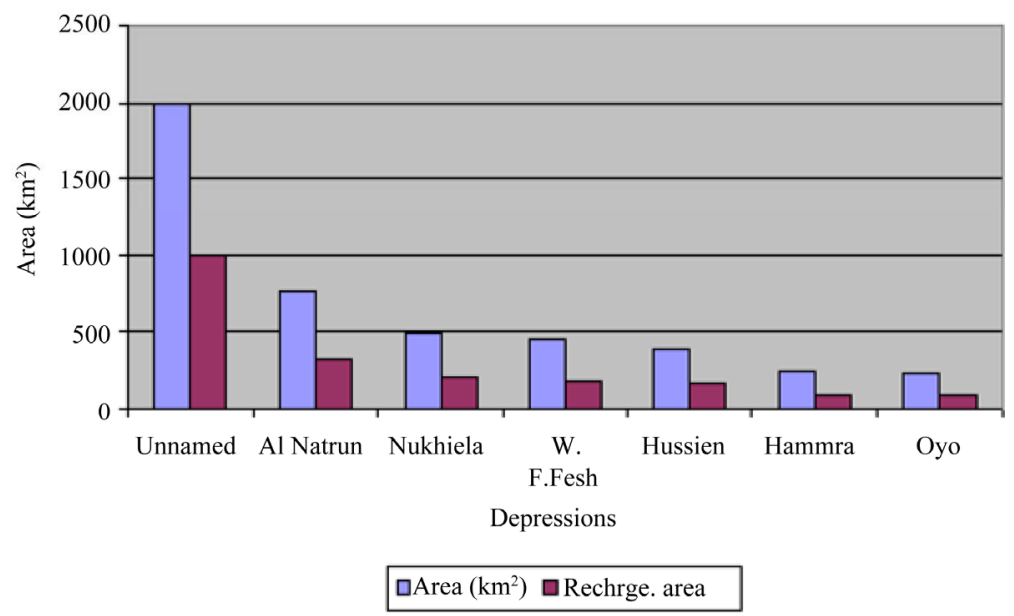

Figure 9. Total area and percentage of recharge area of each depression in the Northern Darfur Paleolake. 
groundwater exploration prior to geophysical survey and agriculture designs.

\section{REFERENCES}

[1] A. M. Omer, "Water Sources and Environment in Sudan," Network for Water and Sanitation, Vol. 4, No. 3, 1997, pp. 5-7.

[2] C. V. Haynes, "Oyo: A Lost Oasis of the Southern Libyan Desert,” The Geographical Journal, Vol. 155, No. 2, 1989, pp. 189-195. doi:10.2307/635060

[3] R. K. Farnsworth, E. C. Brrett and M. S. Dhanju, “Application of Remote Sensing to Hydrology Including Groundwater," United Nations Educational Scientific and Cultural Organization, Paris, 1984.

[4] A. Ho, "Gravity and Seismic Refraction Measurements for Deep Ground Water Search in Southern Darfur Region, Sudan," NWWA Conference on Surface and Borehole Geophysical Methods in Ground Water Investigations, Fort Worth, 12-14 February 1985, pp. 106-120.

[5] A. M. Omer, "Focus on Groundwater in Sudan," Environmental Geology, Vol. 41, No. 8, 2002, pp. 972-976. doi:10.1007/s00254-001-0476-9

[6] F. Wendorf, A. Close, R. Schild, R. Said, C. V. Haynes, A. Gautier and N. Hadidi, "Late Pleistocene and Recent Climatic Changes in the Egyptian Sahara," Geographical Journal, Vol. 143, No. 2, 1977, pp. 211-234. doi:10.2307/1795874

[7] J. McCauley, G. Schaber, C. Breed, C. V. Haynes, J. Grolier, B. Issawi, C. Elachi and R. Blom, "Subsurface Valleys and Geoarchaeology of Egypt and Sudan Revealed by RADAR,” Science, Vol. 218, 1982, pp. 1004-1020. doi:10.1126/science.218.4576.1004

[8] H. Pachur and F. Rottinger, "Evidence for a Large Extended Paleolake in the Eastern Sahara as Revealed by Space Borne Radar Lab Images," Remote Sensing of Environment, Vol. 61, No. 3, 1997, pp. 437-440. doi:10.1016/S0034-4257(96)00210-6

[9] I. Florinsky and G. A. Kuryakova, "Influence of Topography on Some Vegetation Cover Properties," Catena, Vol. 27, No. 2, 1996, pp. 123-141. doi:10.1016/0341-8162(96)00005-7

[10] J. Ritchie and C. Haynes, "Holocene Vegetation Zonation in the Eastern Sahara,” Nature, Vol. 330, No. 6194, 1987, pp. 645-647. doi:10.1038/330645a0

[11] H. Pachur and P. Hoelzmann, "Paleoclimatic Implications of late Quaternary Lacustrine Sediments in Western Nubia, Sudan," Quaternary Research, Vol. 36, No. 3, 1991, pp. 257-276. doi:10.1016/0033-5894(91)90002-M

[12] H. J. Pachur and F. Rottinger, "Evidence for a Large Extended Paleolake in the Eastern Sahara as Revealed by Spaceborne Radar Lab Images," Remote Sensing of Environment, Vol. 61, No. 3, 1997, pp. 437-440. doi:10.1016/S0034-4257(96)00210-6

[13] P. Hoelzmann, B. Keding, H. Berke, S. Kropelin and H. Kruse, "Environmental Change and Archaeology: Lake Evolution and Human Occupation in the Eastern Sahara during the Holocene,” Palaeogeography, Palaeoclima- tology, Palaeoecology, Vol. 169, 2001, pp. 193-217. doi:10.1016/S0031-0182(01)00211-5

[14] K. J. Bhang, F. W. Schwartz and A. Braun, "Verification of the Vertical Error in C Band Srtm Dem Using Icesat and Landsat-7, Otter Tail County Mn,” IEEE Transaction of Geoscience \& Remote Sensing, Vol. 45, No. 1, 2007, pp. 36-44. doi:10.1109/TGRS.2006.885401

[15] K. J. Bhang and F. W. Schwartz, "Limitations in the Hydrologic Application of C Band Srtm Dems in Low Relief Settings," IEEE Geoscience and Remote Rensing Letters, Vol. 5, No. 3, 2008, pp. 497-501. doi:10.1109/LGRS.2008.920712

[16] L. E. Roth and C. Elachi, "Coherent Electromagnetic Losses by Scattering from Volume in Homogeneities," IEEE Transactions of the Antennas and Propagation, Vol. 23, 1975, pp. 674-675. doi:10.1109/TAP.1975.1141170

[17] G. Schaber, J. Mccauley and C. Breed, "The Use of Multifrequency and Polarimetric SIR-C/X-SAR Data in Geologic Studies of Bir Safsaf, Egypt," Remote Sensing of Environment, Vol. 59, No. 2, 1997, pp. 337-363. doi:10.1016/S0034-4257(96)00143-5

[18] E. Ghoneim and F. El-Baz, "The Application of Radar Topographic Data to Mapping of a Mega-Paleodrainage in the Eastern Sahara," Journal of Arid Environments, Vol. 69, No. 4, 2007, pp. 658-675. doi:10.1016/j.jaridenv.2006.11.018

[19] I. D. Moore, P. E. Gessler, G. A. Nielsen and G. A. Peterson, "Soil Attribute Prediction Using Terrain Analysis," Soil Science Society of America Journal, Vol. 57, No. 2, 1993, pp. 443-452. doi:10.2136/sssaj1993.03615995005700020026x

[20] I. Florinsky and G. A. Kuryakova, "Influence of Topography on Some Vegetation Cover Properties," Catena, Vol. 27, No. 2, 1996, pp. 123-141. doi:10.1016/0341-8162(96)00005-7

[21] P. A. Goovaerts, “Geostatistical Approaches for Incorporating Elevation into the Spatial Interpolation of Rainfall,” Journal of Hydrology, Vol. 228, No. 1-2, 2000, pp. 113-129. doi:10.1016/S0022-1694(00)00144-X

[22] M. M. Valeriano and O. A. Carvalho Jr., "GeoprocesSamento de Modelos Digitais de Elevac-a o Para Mapeamento da Curvature Horizontal em Microbacias," Revista Brasileira de Geomorfologia, Vol. 4, No. 1, 2003, pp. 17-29.

[23] D. K. Molna'r and P. Y. Julien, "Estimation of Upland Erosion Using GIS,” Computers \& Geosciences, Vol. 24, No. 2, 1998, pp. 183-192. doi:10.1016/S0098-3004(97)00100-3

[24] P. J. J. Desmet and G. Govers, “A GIS Procedure for Automatically Calculating the USLE LS Factor on Topographically Complex Landscape Units,” Journal of Soil and Water Conservation, Vol. 51, No. 5, 1996, pp. 427433.

[25] L. E. Band, "Topographic Partition of Watersheds with Digital Elevation Models," Water Resources Research, Vol. 22, No. 1, 1986, pp. 15-24. doi:10.1029/WR022i001p00015

[26] G. Miliaresis, “Geomorphometric Mapping of Zagros 
Ranges at Regional Scale,” Computers \& Geosciences, Vol. 27, No. 7, 2001, pp. 715-728. doi:10.1016/S0098-3004(00)00168-0

[27] W. Iskander, “An Appraisal of Ground Water Resources of Zalingei Area-Darfur Province-Sudan,” M.Sc. Thesis, University of Arizona, Tucson, 1969.

[28] B. Rabus, M. Eineder, A. Roth and R. Bamler, "The Shuttle Radar Topography Mission-A New Class of Digital Elevation Models Acquired by Space Borne Radar,” ISPRS Journal of Photogrammetry and Remote Sensing, Vol. 57, 2003, pp. 241-262. doi:10.1016/S0924-2716(02)00124-7

[29] ftp://e0srp01u.ecs.nasa.gov/srtm

[30] A. Jarvis, H. Reuter, A. Nelson and E. Guevara, "HoleFilled Seamlen SRTM Data v3,” 2006. $\mathrm{ftp}: / / \mathrm{e} 0$ srp01u.ecs.nasa.gov/srtm

[31] http://srtm.csi.cgiar.org/Index.asp

[32] www.Googleearth.com

[33] http://www.gdem.aster.ersdac.or.jp/search.jsp

[34] Hydrological Map of Sudan, "Scale 1:2000000, Ministry of Energy and Mines,” Khartoum, 1989.

[35] P. L. Guth, “Geomorphometry in MICRODEM,” In: T. Hengl and H. I. Reuter, Eds., Geomorphometry: Concepts, Software, Applications. Developments in Soil Science Series, Elsevier, Amsterdam, 2008, pp. 351-366.

[36] A. H. Ehsani and F. Quiel, “Application of Self Organizing Map and SRTM Data to Characterize Yardangs in the Lut Desert, Iran,” Remote Sensing of Environment, Vol. 112, 2008, pp. 3284-3294. doi:10.1016/j.rse.2008.04.007

[37] D. G. Tarboton, “A New Method for the Determination of Flow Directions and Contributing Areas in Grid Digital Elevation Models," Water Resources Research, Vol. 33, 1997, pp. 309-319. doi:10.1029/96WR03137

[38] M. Klimanek, “Geoinformation Support of Derived Mapping Based on Digital Terrain Model,” Ph.D. Thesis, University of Agriculture and Forestry Brno, Brno, 2010.

[39] S. Jenson and J. Domingue, "Extracting Topographic Structure from Digital Elevation Model Data for Geographic
Information System Analysis,” Photogrammetric Engineering and Remote Sensing, Vol. 54, No. 11, 1988, pp. 15931600.

[40] J. F. O'callaghan and D. M. Mark, “The Extraction of Drainage Networks from Digital Elevation Data," Computer Vision, Graphics, and Image Processing, Vol. 28, No. 3, 1984, pp. 323-344. doi:10.1016/S0734-189X(84)80011-0

[41] Environmental Research Institute, "Using ArcGIS Geostatistical Analyst Arc GIS software Manual,” Redlands, 2007.

[42] I. S. Evans, "General Geomorphology, Derivatives of Altitude and Descriptive Statistics,” In: R. J. Chorley, Ed., Spatial Analysis in Geomorphology, Methuen \& Co. Ltd, London, 1972, pp. 17-90.

[43] J. Wood, "The Geomorphologic Characterization of Digital Elevation Models,” Ph.D. Thesis, University of Leicester, Leicester, 1996.

[44] P. A. Shary, S. L. Sharaya and A. V. Mitusov, "Fundamental Quantitative Methods F Land Surface Analysis," Geoderma, Vol. 107, No. 1-2, 2002, pp. 1-32. doi:10.1016/S0016-7061(01)00136-7

[45] A. Shatta, "Remarks on the Regional Geological Structure of the Ground Water Reservoir of E1-Kharga and Dakhla Oases,” Bulletin Society Geography, Vol. 34, 1961, pp. 177-186.

[46] J. Ball, "Problems of the Libyan Desert," The Geographical Journal, Vol. 70, No. 1, 1927, pp. 21-38.

[47] G. Caton-Thompson, "Kharga Oases in Prehistory with A Physiographic Introduction by E. W. Gardner," University of London, Athlone Press, London, 1952.

[48] I. Samy, "Remote sening for Hydrological Application in the Vacinity of AlDhied,” M.Sc. Thesis, University Technology, Malaysia (UTM), Kuala Lumpur, 2006.

[49] R. N. Subba, "Groundwater Potential Index in a Crystalline Terrain Using Remote Sensing Data,” Environmental Geology, Vol. 50, No. 7, 2006, pp. 1067-1076. doi:10.1007/s00254-006-0280-7 